\title{
A simple multi-wavelength spectroscopic method for the determination of carboxyl group content in nanocellulose
}

\author{
Ning Yan $\cdot$ Xin-Sheng Chai $\cdot$ Troy Runge $\mathbb{D}$
}

Received: 29 November 2020/Revised: 18 January 2021/ Accepted: 27 January 2021 / Published online: 14 February 2021

(C) The Author(s) 2021

\begin{abstract}
This study describes a multi-wavelength spectroscopic method for the determination of carboxyl group content of nanocellulose. Methylene blue (MB) was used as a color indicator, which can bind to the carboxyl groups in nanocellulose to form a R-COOMB complex with a binding ratio of $1: 1$, although the spectrums of $\mathrm{MB}$ and $\mathrm{R}-\mathrm{COOMB}$ at 500-750 $\mathrm{nm}$ are overlapped, and solid impurities could cause spectral interference. To solve these issues, a multi-wavelength spectroscopic measurement on a MB and nanocellulose mixture solution technique and mathematical model were developed,
\end{abstract}

N. Yan

College of Bioresources Chemical and Materials

Engineering, Shaanxi Provincial Key Laboratory of

Papermaking Technology and Specialty Paper

Development, National Demonstration Center for

Experimental Light Chemistry Engineering Education,

Shaanxi University of Science and Technology, Longshuo

Road, Weiyang District, Xi'an 710021, China

e-mail: nyan@sust.edu.cn

\section{X.-S. Chai}

State Key Laboratory of Pulp and Paper Engineering, South China University of Technology, No. 381, Wushan Road, Tianhe District, Guangzhou 51064, China e-mail: xschai@scut.edu.cn

\section{T. Runge $(\bowtie)$}

Department of Biological System Engineering, University of Wisconsin-Madison, 460 Henry Mall, Madison,

WI 53706, USA

e-mail: trunge@wisc.edu allowing the content of carboxyl groups in nanocellulose to be quantified. The results showed that the method has good measurement precision and accuracy as compared with those measured by a reference method. The method is simple and requires only a small sample size for testing and thus makes it suitable for nanocellulose related research and applications.

Keywords Nanocellulose - Carboxyl group · Methylene blue $\cdot$ Multi-wavelength spectroscopy

\section{Introduction}

Nanocellulose is cellulosic material consisting of nanosized fibrils with sizes ranging from 1 to 100 $\mathrm{nm}$ in at least one dimension (Dufresne 2013). In addition to being degradable and renewably sourced, nanocellulose has unique advantages of high specific surface area, strength, Young's modulus and transparency (Abitbol et al. 2016). These properties allow for many potential applications in several including coatings (Liu et al. 2017; Hassan et al. 2016), biomedicine (Jorfi and Foster 2015), and energy electronics (Kuzmenko et al. 2015). The introduction of carboxylic group on the cellulose is beneficial to the production and functional modification of nanocellulose-based materials (Saito and Isogai 2005; Johnson et al. 2011; Fujisawa et al. 2011). This can be achieved by the chemical treatments, typically with TEMPO (2,2,6,6-tetramethylpiperidine-1-oxyl radical)- $\mathrm{NaBr}$ - 
$\mathrm{NaClO}$ oxidation (Isogai et al. 2011). Since the carboxyl content is directly related to the properties and performance of the nanocellulose based products, a simple method that can effectively determine the carboxylic group content is critical for nanocellulose development and research.

Currently, neutralization based conductometric titration method (Junka et al. 2013; Besbes et al. 2011) is typically used in the determination of the carboxyl content in cellulose samples. In this method, excess hydrochloric acid is used to convert the $-\mathrm{COONa}$ in cellulose to $-\mathrm{COOH}$ form and then back-titrated to the -COONa form with a standard $\mathrm{NaOH}$ solution. A titration curve is created by plotting the conductivity electrode signal change against the volume of the standard $\mathrm{NaOH}$ solution added. The carboxyl content of the cellulose sample can be calculated according to the volume of $\mathrm{NaOH}$ between the two transition points. The major problem of this method for nanocellulose is that the acidified solution is very viscous, which hinders the reaction between - $\mathrm{COOH}$ and hydroxide ions and thus makes the testing very time-consuming. Although this problem can be solved by a significant dilution, this causes error since the conductivity change at the transition points comes becomes less distinct. There are also methods available for the determination of carboxyl group in cellulose based on the advanced instruments, such as headspace gas chromatography (Chai et al. 2003; Wu et al. 2018) and nuclear magnetic resonance (NMR) (Capitani et al. 2000; Kumar et al. 1999). However, these methods require time-consuming pretreatment procedures and expensive instrumentation.

In a previous study (Davidson 1948), a spectroscopic method was used to determine the carboxyl content on solid cellulose fibers, based on measuring the absorbance (at the wavelength of $664 \mathrm{~nm}$ ) of the remaining methylene blue (MB) in the filtrate (after the adsorption with fiber sample). After subtracting by the absorbance from the blank solution (i.e., before the fiber' adsorption experiment), the net absorbance of $\mathrm{MB}$ was found to be proportional to its concentration. However, this method fails to measure the content of carboxyl groups in dissolved or partially dissolved samples (e.g., granular oxidized starch), because MB bounded on $\mathrm{R}_{-} \mathrm{COO}^{-}$in the dissolved sample absorptions overlaps with the spectrum of the pure MB.

The objective of this work was to develop a simple spectroscopic method for the determination of carboxyl group content in nanocellulose. $\mathrm{MB}$ was used as a color indicator (to form a R-COOMB complex) in this method. The main focuses were to find the spectral characteristics of R-COOMB complex; verify the binding ratio of $\mathrm{MB}$ to $-\mathrm{COO}^{-}$in nanocellulose; and establish a corrective method to solve the overlap from the mixture spectrum in the presence of these two species. The present method provides an efficient tool to determine the carboxyl group content in the nanocellulose related research and applications.

\section{Experimental}

Apparatus

A UV/Vis spectrophotometer (UV-8453, Agilent Technologies, USA) equipped with a $10-\mathrm{mm}$ silica cell was used for the spectroscopic measurements.

Chemicals and sample preparation

Analytical-grade MB was purchased from Alfa Aesar (Massachusetts, USA). A methylene blue $(31.3 \mu \mathrm{mol} /$ L) solution was analytically prepared using deionized water (resistivity $\geq 18.2 \mathrm{M} \Omega \mathrm{cm}$ ).

Aspen chips were obtained from Dane County, WI, USA. The GVL pulp and bleached kraft pulp were prepared from aspen chips according to the procedures as previously described (Isogai et al. 2011; Chen et al. 2019). Nanocellulose samples were prepared from GVL pulp and bleached kraft pulp by TEMPOmediated oxidation, followed by a homogenization treatment.

Analytical procedures

Equal volume of a nanocellulose solution sample and methylene blue solution were transferred into a $20 \mathrm{~mL}$ vial and mixed well. The UV-Vis spectrum of the solution was measured and the absorbances at the wavelength range of interest were recorded. Distilled water was used as the blank in the UV-Vis measurements. 


\section{Results and discussion}

The spectrum of RCOOMB in nanocellulose

Methylene blue $\left(\mathrm{MB}^{+} \mathrm{Cl}^{-}\right)$(its structural formula is shown in Fig. 1) is a cationic basic dye that is soluble in water. By exchange $\mathrm{MB}^{+}$ions with $\mathrm{Na}^{+}$or $\mathrm{H}^{+}$in the carboxyl groups of cellulosic material, a new complex $\left(\mathrm{R}-\mathrm{COO}^{-} \mathrm{MB}^{+}\right)$is formed. The reaction can be rewritten as

$$
\mathrm{RCOONa}+\mathrm{MB}^{+} \mathrm{Cl}^{-} \rightleftharpoons \mathrm{RCOOMB}+\mathrm{Na}^{+}+\mathrm{Cl}^{-}
$$

It is expected that the $\mathrm{R}-\mathrm{COO}^{-} \mathrm{MB}^{+}$also has the absorption in the visible wavelength range.

Figure 2 shows the spectrums of $\mathrm{MB}$ and $\mathrm{R}-\mathrm{COO}^{-}$ $\mathrm{MB}^{+}$, in which the spectrum of $\mathrm{R}_{-} \mathrm{COO}^{-} \mathrm{MB}^{+}$was obtained by adding an excessive concentration of nanocellulose into the $\mathrm{MB}$ solution with a fixed concentration $\left(\mathrm{C}_{\mathrm{MB}}=10 \mathrm{mg} / \mathrm{L}\right)$ since nanocellulose has no spectral absorption at this wavelength range. Clearly, the $\mathrm{R}-\mathrm{COO}^{-} \mathrm{MB}^{+}$has a spectrum with a maximum absorbance at $565 \mathrm{~nm}$, it also has significant overlap with the spectrum of MB (from 500 to 750 $\mathrm{nm})$.

The binding ratio of $\mathrm{MB}$ to $-\mathrm{COO}^{-}$ in nanocellulose

The binding ratio (n) of methylene blue to the carboxyl group in nanocellulose was spectroscopically determined as follows. An experiment was performed by adding different concentrations of nanocellulose with known and varying carboxyl group content obtained by the conductivity method to a methylene blue solution with a fixed concentration $(31.3 \mu \mathrm{mol} / \mathrm{L})$. The solutions' absorbance at $565 \mathrm{~nm}$ were measured. As previously noted, both RCOOMB and MB have the<smiles></smiles>

Fig. 1 Chemical structure of methylene blue

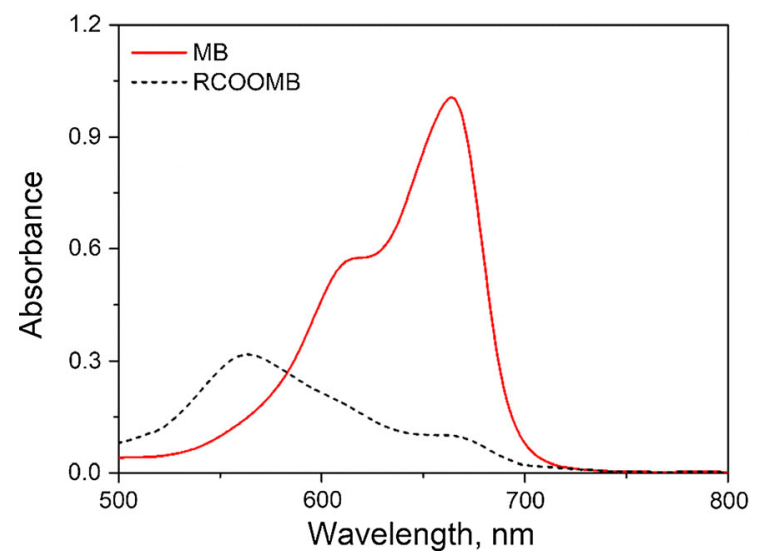

Fig. 2 Absorption spectra of MB and RCOOMB

spectral absorption at $565 \mathrm{~nm}$. Because the contents of carboxyl group added to the MB fixed solutions was known, the absorbance of the residual MB at $565 \mathrm{~nm}$ in the mixture solution can be calculated based on that of the pure MB solution.

To calculate the binding ratio, we considered that in a solution mixture, when the molar ratio of carboxyl group to $\mathrm{MB}\left(\mathrm{C}_{-} \mathrm{COOH}_{\mathrm{CO}} / \mathrm{C}_{\mathrm{MB}}\right)$ is less than 1 , the absorbance at $565 \mathrm{~nm}$ and concentration can be written as

$\mathrm{A}_{\mathrm{M}}=\mathrm{A}_{\mathrm{MB}}^{\text {Residual }}+\mathrm{A}_{\mathrm{RCOOMB}}$

or

$\mathrm{A}_{\mathrm{RCOOMB}}=\mathrm{A}_{\mathrm{M}}-\mathrm{A}_{\mathrm{MB}}^{\text {Residual }}$

and the concentration of the residual $\mathrm{MB}$ can be written as

$$
\mathrm{C}_{\mathrm{MB}}^{\text {Residual }}=\mathrm{C}_{\mathrm{MB}}-\mathrm{C}_{-\mathrm{COOH}}
$$

where $A_{M}, A_{M B}^{\text {Residual }}, A_{R C O O M B}$ represents the total absorbance in a mixture solution, the absorbance of residual $\mathrm{MB}$ and the absorbance of the produced complex RCOOMB at the wavelength of $565 \mathrm{~nm}$, respectively. $\mathrm{C}_{\mathrm{MB}}, \mathrm{C}_{\mathrm{MB}}^{\text {Residual }}, \mathrm{C}_{-\mathrm{COOH}}$ represents the initial concentration of $\mathrm{MB}$, the residual concentration of MB and the concentration of carboxyl group added which is equal to the reacted amount of $\mathrm{MB}$, respectively.

According to Beer's law, the spectral absorbance is proportional to the concentration of the species in the solution, i.e.,

$\mathrm{A}=\mathrm{k} \cdot \mathrm{C}$ 
where $\mathrm{k}$ is a constant.

Divide both sides in Eq. (3) by $\mathrm{C}_{\mathrm{MB}}$ to obtain,

$\frac{\mathrm{C}_{\mathrm{MB}}^{\text {Residual }}}{\mathrm{C}_{\mathrm{MB}}}=1-\frac{\mathrm{C}_{-\mathrm{COOH}}}{\mathrm{C}_{\mathrm{MB}}}$

Combining Eqs. (2-1), (3) and (5) to have

$\mathrm{A}_{\mathrm{RCOOMB}}=\mathrm{A}_{\mathrm{M}}-\mathrm{A}_{\mathrm{MB}} \cdot\left(1-\frac{\mathrm{C}_{-\mathrm{COOH}}}{\mathrm{C}_{\mathrm{MB}}}\right)$

Figure 3 shows the plot of the absorbance of RCOOMB at 565 versus the molar ratio of carboxyl group to $\mathrm{MB}\left(\mathrm{C}_{-} \mathrm{COOH}_{\mathrm{MB}}\right)$ and it can be seen that the absorbance is greatly increased with the molar ratio of $\mathrm{C}_{-} \mathrm{COOH} / \mathrm{C}_{\mathrm{MB}}$ before it is equal to 1 . However, such changes are not significant after the molar ratio of $\mathrm{C}_{-\mathrm{COOH}} / \mathrm{C}_{\mathrm{MB}}$ is greater than 1 . It confirms that the bounding ratio of carboxyl group to $\mathrm{MB}$ is 1 in the solution at the given conditions. In Fig. 3, A and $\mathrm{A}^{\prime}$ are the theoretical absorbance and real absorbance (due to the dissociation) for the RCOOMB in the solution.

The dissociation constant of RCOOMB complex

The dissociation constant of the RCOOMB complex is important to the accuracy of the method, because the larger dissociation constant could cause a larger negative error in the measurement. However, it can be improved by choosing the proper conditions, such as using an excess dosage of MB.

According to Eq. (1), the dissociation constant (K) of RCOOMB can be calculated by

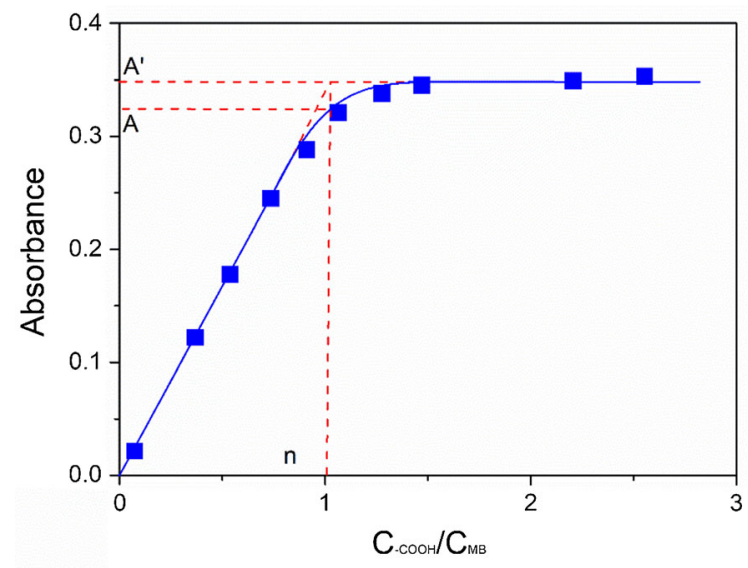

Fig. 3 Determination of binding ratio of RCOOMB complex
$\mathrm{K}=\frac{\left[\mathrm{RCOO}^{-}\right]\left[\mathrm{MB}^{+}\right]}{[\mathrm{RCOOMB}]}$

where $[\mathrm{RCOOMB}],\left[\mathrm{RCOO}^{-}\right]$and $\left[\mathrm{MB}^{+}\right]$represent the concentration of RCOOMB, and carboxyl group and $\mathrm{MB}$ at equilibrium, respectively.

In a mixture of equal moles of carboxyl and MB, we can obtain the following equations at the equilibrium, i.e.,

$$
\begin{aligned}
& {[\mathrm{RCOOMB}]=(1-\alpha) \cdot \mathrm{C}} \\
& {\left[\mathrm{RCOO}^{-}\right]=\left[\mathrm{MB}^{+}\right]=\alpha \cdot \mathrm{C}}
\end{aligned}
$$

where $\mathrm{C}$ is the initial concentration of the carboxyl group or $\mathrm{MB}, 15.6 \mu \mathrm{mol} / \mathrm{L} ; \alpha$ is the degree of dissociation of the complex, which can be calculated by,

$\alpha=\frac{\mathrm{A}^{\prime}-\mathrm{A}}{\mathrm{A}^{\prime}}$

Substituting Eqs. (8) and (9) to (7) to obtain

$\mathrm{K}=\frac{\left[\mathrm{RCOO}^{-}\right]\left[\mathrm{MB}^{+}\right]}{[\mathrm{RCOOMB}]}=\frac{\alpha^{2} \cdot \mathrm{C}}{1-\alpha}$

Based on the absorbance data showed in Fig. 3 and Eqs. (10) and (11), the dissociation constant and the degree of dissociation of RCOOMB is $7.38 \times 10^{-8}$ and $6.64 \%$ (at equal molar ratio), respectively.

The selection of the condition to improve the method accuracy

If the concentration of $\mathrm{MB}$ in the solution is overdosed, i.e., it is $m$ times of the content of carboxyl group on nanocellulose, the degree of dissociation of the complex will change and it can be calculated according to

$\mathrm{K}=\frac{\left[\mathrm{RCOO}^{-}\right]\left[\mathrm{MB}^{+}\right]}{[\mathrm{RCOOMB}]}=\frac{m \cdot \alpha^{2} \cdot \mathrm{C}}{1-\alpha}$

where $\mathrm{C}$ is the initial concentration of the carboxyl group.

Based on Eq. (12), the calculated $\alpha$ is $3.00 \%$ if $m$ is 5 . Thus, the error caused by the dissociation of the complex can be considered negligible under these excess MB concentration conditions. 
Effect of possible interference on the spectral measurement

Figure 4 shows the spectrums of nanocellulose $(80 \mathrm{mg} / \mathrm{L})$ produced from the different pulp species or methods, which are named as cellulose nanofibers (CNF), Tempo-oxidized cellulose nanofibers prepared from kraft pulp (KTCNF) and from gamma-valerolactone (GTCNF), respectively. It can be seen that any solid impurity such as the presence of fiber fines could cause the absorption in the whole wavelength range due to the light scattering and result in a baseline shift. if the interference is significant in a sample, it will have an impact to the spectral measurement.

Figure 4 shows that the baseline shifting caused by the solid impurity is approximately linear. Thus, the wavelength-dependent absorbance of the interference in the range of 500-750 $\mathrm{nm}$ can be expressed as

$\mathrm{A}_{\lambda_{i}}^{\mathrm{T}}=\mathrm{A}_{750}+\mathrm{m} \cdot\left(\lambda_{i}-750\right)$

where $\mathrm{m}$ is the slope of the spectrum of nanocellulose in the range of 400 to $750 \mathrm{~nm}$, which is $-2.0 \times 10^{-5}$ based on the spectra shown in Fig. 4.

According to Fig. 3, it was observed that there was no absorbances from either MB or RCOOMB at the wavelength of $750 \mathrm{~nm}$. Therefore, the absorbance at $750 \mathrm{~nm}$ can be used to subtract the spectral interferences caused by the impurity in nanocellulose samples at the interest wavelength range.

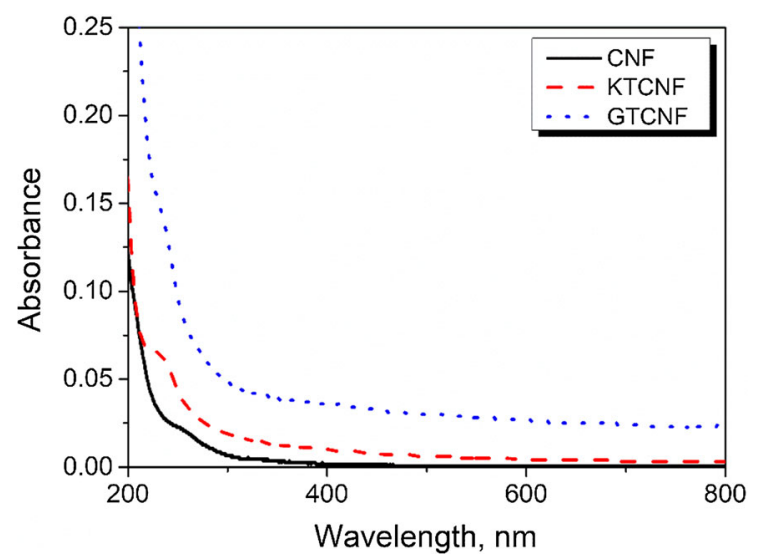

Fig. 4 Spectra of the nanocellulose solutions
Establishment of multi-wavelength spectroscopic method for measuring carboxyl content

When the MB is in great excess, the absorbance of the mixture at a given wavelength can be expressed by

$A_{\lambda}=k_{1} A_{\lambda}^{1}+k_{2} A_{\lambda}^{2}+A_{\lambda}^{T}$

Extending the above equation to a multicomponent system, the absorbances at the multi-wavelength can be expressed by the following matrix,

$$
\begin{aligned}
{\left[\begin{array}{c}
A_{\lambda_{1}} \\
A_{\lambda_{2}} \\
\vdots \\
A_{\lambda_{n}}
\end{array}\right]=} & {\left[\begin{array}{cccc}
A_{\lambda_{1}}^{1} & A_{\lambda_{1}}^{2} & \ldots & A_{\lambda_{1}}^{n} \\
A_{\lambda_{2}}^{1} & A_{\lambda_{2}}^{2} & \ldots & A_{\lambda_{2}}^{n} \\
\vdots & \vdots & \ddots & \vdots \\
A_{\lambda_{n}}^{1} & A_{\lambda_{n}}^{2} & \ldots & A_{\lambda_{n}}^{n}
\end{array}\right]\left[\begin{array}{c}
k_{1} \\
k_{2} \\
\vdots \\
k_{n}
\end{array}\right] } \\
& +\left[\begin{array}{c}
m \cdot\left(\lambda_{1}-750\right) \\
m \cdot\left(\lambda_{2}-750\right) \\
\vdots \\
m \cdot\left(\lambda_{n}-750\right)
\end{array}\right]+\left[\begin{array}{c}
e_{\lambda_{1}} \\
e_{\lambda_{2}} \\
\vdots \\
e_{\lambda_{n}}
\end{array}\right]
\end{aligned}
$$

where $A_{\lambda_{i}}^{j}, k_{i}$ and $e_{i}$ represent the absorbance of the component $\mathrm{j}$ at the wavelength of $\lambda_{i}$, the fitting coefficient and error term, respectively $(i=1,2, \ldots, n)$; $A_{\lambda}^{T}$ is the absorbance contributed by nanocellulose turbidity at wavelength of $\lambda_{i}$ in a mixed solution.

In this study, the absorbance values of the mixed solution (two-component system of unknown concentration) at 500-750 nm (i = 1-250) were measured, and all the data were imported into Eq. (15). We can solve the equation for $\mathrm{k}_{1}$ and $\mathrm{k}_{2}$ by seeking values that minimize the sum of square of the errors $\left(\sum \mathrm{e}_{\lambda_{\mathrm{i}}}^{2}\right)$ using the numerical analysis software (Solver in Microsoft

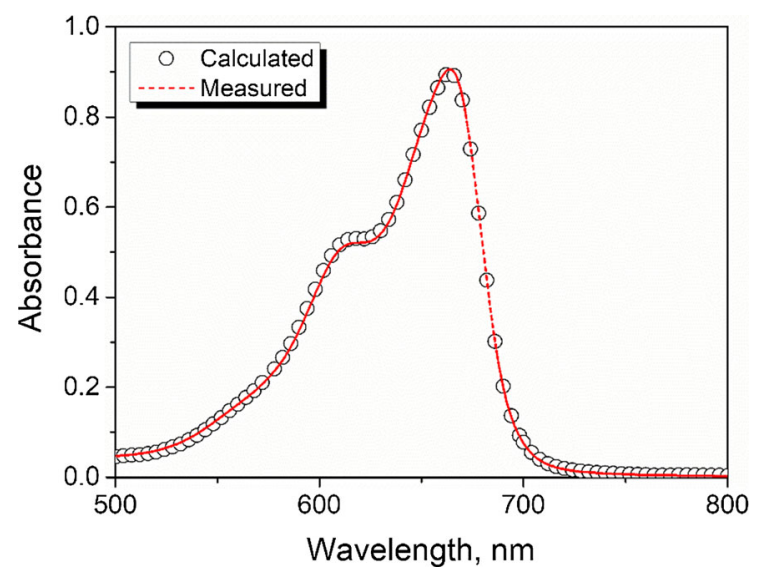

Fig. 5 Calculated (by Eq. 15) and measured spectrum for a mixture solution 
Excel was used in this experiment). Figure 5 shows an excellent match between the spectrum calculated by Eq. (15) at a minimized sum of squared errors $\left(\sum \mathrm{e}_{\lambda_{\mathrm{i}}}^{2}\right)$ and the measured spectrum in a mixture solution of $\mathrm{MB}$ and nanocellulose.

The $\mathrm{k}$ value is obtained by the best fitting, from which the carboxylic acid content in the nanocellulose sample can be calculated by

$\mathrm{C}_{-\mathrm{COOH}}(\mu \mathrm{mol} / \mathrm{L})=1000 \cdot \frac{\mathrm{k}_{1} \mathrm{C}_{\mathrm{MB}}}{\mathrm{C}}=3.13 \times 10^{4} \cdot \frac{\mathrm{k}_{1}}{\mathrm{C}}$

where $\mathrm{C}_{\mathrm{MB}}$ is the initial concentration of $\mathrm{MB}, 31.3$ is practical concentration used in this experiment $(\mu \mathrm{mol} /$ $\mathrm{L}$ ); $\mathrm{C}$ is the concentration of nanocellulose, $\mathrm{mg} / \mathrm{L}$.

\section{Method evaluation}

The repeatability of the proposed method was evaluated using a quintuplicate test of MB and nanocellulose mixed solution with the concentration of $\mathrm{MB}$ at $31.3 \mu \mathrm{mol} / \mathrm{L}$ (which was 5 times more concentrated than the $-\mathrm{COOH}$ content in nanocellulose). As The results shown in Table 1 indicate that the present method has an excellent measurement precision, in which the relative standard deviations (RSDs) are less than $2.3 \%$.

To verify the accuracy of the method, the carboxyl group contents of nanocellulose from two types of pulps with different oxidation treatment were tested by both the reference method (i.e., conductivity titration) and the present spectroscopic method. The feasibility study showed that the concentration of nanocellulose in the testing solution can affect the results of the method, the use of a lower sample concertation. e.g., less than $2.5 \mathrm{mg} / \mathrm{L}$ (assuming the content of $-\mathrm{COO}^{-}$ groups is $1 \mathrm{mmol} / \mathrm{g}$ ), could achieve a good agreement with those measured by the reference method.

Table 2 lists the comparison results between the proposed and the reference methods for the nanocellulose samples from the different process conditions. Sample concentrations in the tested solutions were within $2.5 \mathrm{mg} / \mathrm{L}$. It can be seen from the table that the relative differences between the data measured by these two methods on these samples are less than $5.0 \%$, indicating that the developed method is suitable to be used for the determination of carboxyl group content in nanocellulose samples.
Table 1 Repeatability testing

\begin{tabular}{lllllll}
\hline Test no. & \multicolumn{7}{l}{ COOH content, $\mu \mathrm{mol} / \mathrm{g}$} & & & \\
\cline { 2 - 7 } & Sample 1 & Sample 2 & Sample 3 & Sample 4 & Sample 5 & Sample 6 \\
\hline 1 & 820 & 1086 & 732 & 932 & 1223 & 890 \\
2 & 802 & 1048 & 724 & 940 & 1199 & 872 \\
3 & 814 & 1095 & 721 & 956 & 1194 & 882 \\
4 & 932 & 1072 & 713 & 937 & 1260 & 869 \\
5 & 827 & 1116 & 725 & 964 & 1218 & 903 \\
Average & 819 & 1083 & 723 & 946 & 1219 & 883 \\
RSD, $\%$ & 1.4 & 2.3 & 0.9 & 1.4 & 2.1 & 1.6 \\
\hline
\end{tabular}

Table 2 Comparison of the methods

\begin{tabular}{llccc}
\hline Sample type & NaClO dosage to pulp mmol/g & \multicolumn{2}{l}{ COOH, $\mu \mathrm{mol} / \mathrm{g}$} & \multirow{2}{*}{ Relative difference, $\%$} \\
\cline { 3 - 5 } & & Present $(\mathrm{n}=3)$ & Reference $(\mathrm{n}=3)$ & -1.32 \\
\hline Bleached kraft pulp & 2.4 & $819 \pm 13$ & $830 \pm 10$ & -2.40 \\
& 4.8 & $1083 \pm 9$ & $1110 \pm 70$ & 3.18 \\
GVL pulp & 2.4 & $723 \pm 23$ & $700 \pm 30$ & 4.23 \\
& 4.8 & $1219 \pm 15$ & $1170 \pm 30$ & \\
\hline
\end{tabular}




\section{Conclusions}

A method for the determination of carboxyl group content of nanocellulose has been developed, based on a multi-wavelength spectroscopic measurement on a solution with $\mathrm{MB}$ and nanocellulose mixture. The method is simple to use in the determination of carboxyl group content of nanocellulose for related research and applications.

Acknowledgments The authors acknowledge the financial support from the National Key R\&D Program of China (Grant No. 2018YFD0400701), the Natural Science Foundation of China (Project Nos. 21576105 and 51409287) and the United States Department of Agriculture National Institute of Food and Agriculture, under ID number WIS03007.

\section{Compliance with ethical standards}

Conflict of interest There are no conflict of interest to declare.

Open Access This article is licensed under a Creative Commons Attribution 4.0 International License, which permits use, sharing, adaptation, distribution and reproduction in any medium or format, as long as you give appropriate credit to the original author(s) and the source, provide a link to the Creative Commons licence, and indicate if changes were made. The images or other third party material in this article are included in the article's Creative Commons licence, unless indicated otherwise in a credit line to the material. If material is not included in the article's Creative Commons licence and your intended use is not permitted by statutory regulation or exceeds the permitted use, you will need to obtain permission directly from the copyright holder. To view a copy of this licence, visit http://creativecommons.org/licenses/by/4.0/.

\section{References}

Abitbol T, Rivkin A, Cao Y et al (2016) Nanocellulose, a tiny fiber with huge applications. Curr Opin Biotech 39:76-88. https://doi.org/10.1016/j.copbio.2016.01.002

Besbes I, Sabrine A, Sami B (2011) Nanofibrillated cellulose from TEMPO-oxidized eucalyptus fibres: effect of the carboxyl content. Carbohydr Polym 84:975-983. https:// doi.org/10.1016/j.carbpol.2010.12.052

Capitani D, Porro F, Segre AL (2000) High field NMR analysis of the degree of substitution in carboxymethyl cellulose sodium salt. Carbohydr Polym 42:283-286. https://doi.org/ 10.1016/S0144-8617(99)00173-3

Chai XS, Hou QX, Zhu JY et al (2003) Carboxyl groups in wood fibers. 1. Determination of carboxyl groups by headspace gas chromatography. Ind Eng Chem Res 42:5440-5444. https://doi.org/10.1021/ie020972a
Chen M, Ma Q, Zhu JY et al (2019) GVL pulping facilitates nanocellulose production from woody biomass. Green Chem 21:5316-5325. https://doi.org/10.1039/C9GC01490J

Davidson GF (1948) 6-the acidic properties of cotton cellulose and derived oxycelluloses. Part II. The absorption of methylene blue. J Text I T 39:T65-T86. https://doi.org/10. 1080/19447024808659403

Dufresne A (2013) Nanocellulose: a new ageless bionanomaterial. Mater Today 16:220-227. https://doi.org/10.1016/j. mattod.2013.06.004

Fujisawa S, Okita Y, Fukuzumi H et al (2011) Preparation and characterization of TEMPO-oxidized cellulose nanofibril films with free carboxyl groups. Carbohydr Polym 84:579-583. https://doi.org/10.1016/j.carbpol.2010.12.029

Hassan EA, Hassan ML, Abou-Zeid RE et al (2016) Novel nanofibrillated cellulose/chitosan nanoparticles nanocomposites films and their use for paper coating. Ind Crops Prod 93:219-226. https://doi.org/10.1016/j.indcrop.2015.12.006

Isogai A, Saito T, Fukuzumi H (2011) TEMPO-oxidized cellulose nanofibers. Nanoscale 3:71-85. https://doi.org/10. 1039/C0NR00583E

Johnson RK, Zink-Sharp A, Glasser WG (2011) Preparation and characterization of hydrophobic derivatives of TEMPOoxidized nanocelluloses. Cellulose 18:1599-1609. https:// doi.org/10.1007/s10570-011-9579-y

Jorfi M, Foster EJ (2015) Recent advances in nanocellulose for biomedical applications. J Appl Polym Sci 132:41719. https://doi.org/10.1002/app.41719

Junka K, Filpponen I, Lindström T et al (2013) Titrimetric methods for the determination of surface and total charge of functionalized nanofibrillated/microfibrillated cellulose (NFC/MFC). Cellulose 20:2887-2895. https://doi.org/10. 1007/s10570-013-0043-z

Kumar V, Yang T (1999) Analysis of carboxyl content in oxidized celluloses by solid-state $13 \mathrm{C} \mathrm{CP/MAS} \mathrm{NMR} \mathrm{spec-}$ troscopy. Int J Pharmaceut 184:219-226. https://doi.org/ 10.1016/S0378-5173(99)00098-8

Kuzmenko V, Naboka O, Haque M et al (2015) Sustainable carbon nanofibers/nanotubes composites from cellulose as electrodes for supercapacitors. Energy 90:1490-1496. https://doi.org/10.1016/j.energy.2015.06.102

Liu C, Du H, Dong L et al (2017) Properties of nanocelluloses and their application as rheology modifier in paper coating. Ind Eng Chem Res 56:8264-8273. https://doi.org/10.1021/ acs.iecr.7b01804

Saito T, Isogai A (2005) Ion-exchange behavior of carboxylate groups in fibrous cellulose oxidized by the TEMPO-mediated system. Carbohydr Polym 61:183-190. https://doi. org/10.1016/j.carbpol.2005.04.009

Wu N, Wan X, Liu B et al (2018) A simple and efficient headspace gas chromatographic method for the determination of carboxyl groups in nanofibrillated cellulose. Cellulose 25:953-959. https://doi.org/10.1007/s10570017-1614-1

Publisher's note Springer Nature remains neutral with regard to jurisdictional claims in published maps and institutional affiliations. 